\title{
Jean-Paul Sartre e o Terceiro Mundo (1947-1979)
}

\section{Jean-Paul Sartre and the Third World (1947-1979)}

DOI: $10.46814 /$ lajdv3n5-002

Recebimento dos originais: 01/07/2021

Aceitação para publicação: 31/08/2021

\section{Rodrigo Davi Almeida}

Pós-doutor em História Contemporânea - École des Hautes Études en Sciences Sociales

(EHESS/Paris) - Bolsista CAPES.

Professor Associado II - História Moderna e Contemporânea - Universidade Federal de Mato

Grosso (UFMT/Cuiabá)

Endereço: Av. Fernando Correa da Costa, 2367, Boa Esperança, 78060-900, Cuiabá/MT.

E-mail: rodralvida@yahoo.com.br

\section{RESUMO}

O artigo estuda as posições políticas de Jean-Paul Sartre (1905-1980) relacionadas ao Terceiro Mundo entre 1947 e 1979. Além disso, e a partir delas, enseja reflexões e/ou debates sobre o papel do intelectual na sociedade à luz do conhecimento histórico. As posições políticas de Sartre sobre o Terceiro Mundo constituem, portanto, o objeto deste trabalho cujo problema é a liberdade. Sob o "impacto da História", isto é, no curso dos acontecimentos do Terceiro Mundo - da Guerra da Argélia (1954-1962), da Revolução Cubana (1959-1961) e da Revolução Vietnamita (1946-1976) - Sartre elabora uma nova concepção de liberdade que contradiz sua concepção existencialista anterior. Se a liberdade na concepção existencialista tem uma base teórico-filosófica, situada no plano da ontologia, ou seja, abstrata e individual, sua nova concepção de liberdade tem uma base político-econômica, situada no plano da história, logo, concreta e coletiva. Em outras palavras, Sartre redefine a sua concepção de liberdade à luz de determinados problemas colocados pela emergência do Terceiro Mundo no cenário político mundial. Sob a ótica do marxismo e do método dialético, Sartre procura redefini-la em seus aspectos econômico (como independência), social (como justiça e igualdade), político (como soberania) e cultural (como humanização, em oposição à tortura e ao racismo). O referencial teórico-metodológico provém do marxismo, particularmente, suas contribuições acerca das relações entre indivíduo, sociedade e história. Os principais textos utilizados são os de Michael Löwy, Jean Chesneaux, István Mészáros, Eric Hobsbawm, Gérard Chaliand e Perry Anderson. Esse referencial nos permite pensar a trajetória de Sartre como uma unidade contraditória e as suas posições políticas sobre o Terceiro Mundo tendo em vista o seu fundamento histórico-social. Sartre radicaliza suas ideias e passa a defender o socialismo; intervém contra as guerras coloniais com a assinatura de manifestos, petições, passeatas e comícios populares; divulga as conquistas revolucionárias argelina, cubana e vietnamita ao público mundial, sobretudo, por meio da revista Les Temps Modernes; propõe a criação de um tribunal internacional para julgar os crimes de guerra norte-americanos contra a população vietnamita. Nessa esteira, devemos entender a afirmação de Sartre o "homem é possível" que contradiz a sua máxima ontológica o "homem é uma paixão inútill". Enfim, para Sartre, o "problema humano" - a liberdade - somente pode ser resolvido em termos de produção e de relações sociais de produção de tipo socialista.

Palavras-chave: Jean-Paul Sartre, posições políticas, liberdade, revolução, Terceiro mundo. 


\section{ABSTRACT}

The article studies the political positions of Jean-Paul Sartre (1905-1980) related to the Third World between 1947 and 1979. In addition, and based on them, it encourages reflections and/or debates about the role of the intellectual in society in the light of historical knowledge. Sartre's political positions on the Third World constitute, therefore, the object of this work whose problem is freedom. Under the "impact of history," that is, in the course of Third World events - from the Algerian War (1954-1962), the Cuban Revolution (1959-1961), and the Vietnamese Revolution (1946-1976) - Sartre elaborates a new conception of freedom that contradicts his previous existentialist conception. If freedom in the existentialist conception has a theoretical-philosophical basis, situated on the level of ontology, that is, abstract and individual, his new conception of freedom has a political-economic basis, situated on the level of history, therefore, concrete and collective. In other words, Sartre redefines his conception of freedom in light of certain problems posed by the emergence of the Third World on the world political scene. From the standpoint of Marxism and the dialectical method, Sartre seeks to redefine freedom in its economic (as independence), social (as justice and equality), political (as sovereignty), and cultural (as humanization, in opposition to torture and racism) aspects. The theoretical and methodological framework comes from Marxism, particularly its contributions on the relationship between the individual, society, and history. The main texts used are those by Michael Löwy, Jean Chesneaux, István Mészáros, Eric Hobsbawm, Gérard Chaliand, and Perry Anderson. This reference allows us to think of Sartre's trajectory as a contradictory unit and his political positions on the Third World in view of its social-historical foundation. Sartre radicalizes his ideas and starts to defend socialism; he intervenes against colonial wars by signing manifestos, petitions, marches, and popular rallies; he publicizes the Algerian, Cuban, and Vietnamese revolutionary conquests to the world public, especially through the magazine Les Temps Modernes; he proposes the creation of an international tribunal to judge American war crimes against the Vietnamese population. In this vein, we must understand Sartre's statement that "man is possible" which contradicts his ontological maxim that "man is a useless passion. Finally, for Sartre, the "human problem" - freedom - can only be solved in terms of production and social relations of production of a socialist type.

Keywords: Jean-Paul Sartre, political positions, freedom, revolution, Third World.

\section{INTRODUÇÃO}

O artigo estuda as posições políticas de Jean-Paul Sartre (1905-1980) relacionadas ao Terceiro Mundo. Além disso, e a partir delas, enseja reflexões e/ou debates sobre o papel do intelectual na sociedade à luz do conhecimento histórico. As posições políticas de Sartre sobre o Terceiro Mundo constituem o objeto deste trabalho que tem como problema a liberdade, um dos temas-chave da obra de Sartre. A tese central defendida é que a nova concepção de liberdade de Sartre, elaborada no curso dos acontecimentos do Terceiro Mundo, contradiz sua concepção existencialista anterior. 
Se a liberdade na concepção existencialista tem uma base teórico-filosófica, situada no plano da ontologia, portanto, abstrata e individual, a sua nova concepção de liberdade, elaborada no curso dos acontecimentos do Terceiro Mundo, tem uma base político-econômica, situada no plano da história, logo, concreta e coletiva. Em outras palavras, Sartre redefine sua concepção de liberdade à luz dos problemas colocados pela emergência do Terceiro Mundo no cenário político mundial: a revolução, o papel da juventude e da ideologia na práxis revolucionária, o socialismo, a política considerada sob os ângulos da eficácia e da moralidade, o engajamento e a função política do intelectual (SARTRE, 1994) face à sua "hora histórica".

O referencial teórico-metodológico adotado provém do marxismo, particularmente, as contribuições acerca das relações entre indivíduo, sociedade e história. Os principais textos utilizados são os de Michael Löwy, Lucien Goldmann, Jean Chesneaux, Josep i Fontana, István Mészáros, Eric Hobsbawm, Gérard Chaliand e Perry Anderson. Esse referencial nos permite pensar a trajetória de Sartre como uma "unidade contraditória" (MÉSZÁROS, 1991) e suas posições políticas sobre o Terceiro Mundo tendo em vista o seu fundamento histórico-social. Assim, evitamos reducionismos e simplificações excessivas.

Por um lado, as posições políticas de Sartre a respeito do Terceiro Mundo devem ser vistas como um momento particular e, por outro, inseridas no quadro mais amplo de sua trajetória. Ainda que esta seja uma exigência que se impõe à adequada consideração do "objeto", não demanda, contudo, um estudo ou uma interpretação original, exclusiva. Para tanto, é suficiente lançar mão da literatura a respeito (as biografias sobre Sartre, as suas entrevistas, os diversos estudos marxistas e não marxistas sobre sua obra) para destacar tanto o modo como o seu engajamento político se relaciona à sua trajetória, quanto para demarcar o espaço efetivo que suas preocupações e posições políticas sobre o Terceiro Mundo efetivamente ocupam nela.

Essencialmente, a literatura - marxista - parte do princípio da unidade contraditória na trajetória de Sartre, dada pela sua concepção (e busca) da liberdade. Porém, sua concepção (e busca) da liberdade sofre mutações significativas ao longo da sua trajetória, a ponto de contradizer sua concepção (e busca) inicial da liberdade. A análise filosófica que Sartre sustenta sobre a resistência à tortura, à época da Guerra da Argélia, é tipicamente existencialista. Para Sartre, a delação ou não do supliciado, mediante os castigos corporais impostos pelo carrasco, depende da livre escolha (relacionada ao projeto original) feita pelo indivíduo.

No entanto, as definições e as posições políticas de Sartre sobre o colonialismo, sobre as origens (econômicas) do racismo e, inclusive, da tortura, colocam entre parênteses sua filosofia da liberdade. Em um primeiro momento, a liberdade é definida por Sartre no plano teórico-filosófico, qual seja, do ponto de vista ontológico, portanto, de modo "a-histórico", consequentemente, abstrato 
e no nível estritamente individual. Sob o "impacto da História" e tendo em vista a assunção do marxismo como "filosofia insuperável” (SARTRE, 1986) Sartre passa a considerar a liberdade nos planos concreto e coletivo, isto é, no âmbito da luta de classes. O proletariado europeu e os colonizados do Terceiro Mundo devem, por sofrerem a exploração capitalista, reconhecer sua solidariedade de interesses e lutar juntos para a destruição da sociedade burguesa. Somente por meio da revolução seria exequível a edificação da sociedade socialista, única condição para a efetivação do "reino da liberdade".

Para Sartre, a nova condição para a realização da liberdade entre os homens se refere ao “condicionamento pelas proteínas", como diz numa entrevista a Jacques-Alain Miller. A entrevista realizada em 1960 explicita a posição que Sartre assume e pela qual lutará até o fim de sua vida:

\begin{abstract}
em nome de dois princípios que vêm juntos: primeiro, ninguém pode ser livre se todo mundo não o é; segundo, eu lutarei pela melhoria do nível de vida e das condições de trabalho. A liberdade, não é metafísica, mas prática, é condicionada pelas proteínas. A vida será humana a partir do dia em que todo mundo puder comer e saciar sua fome e todo homem poderá exercer um ofício nas condições que lhe convém. Eu lutarei não somente por um nível de vida melhor, mas também pelas condições de vida democráticas para cada um, pela libertação de todos os explorados, de todos os oprimidos. (SARTRE apud CONTAT; RYBALKA, 1970, p.353)
\end{abstract}

De acordo com Sartre "o curso dos acontecimentos muda os homens" (SARTRE, 1987, p. 137). Quais acontecimentos? A experiência histórica da Segunda Guerra Mundial (1939-1945), a Ocupação nazista (1940-1944), na qual Sartre foi prisioneiro, a Resistência, da qual participara ativamente e a Libertação da França, num primeiro momento. A Guerra da Argélia (1954-1962), a Revolução Cubana (1959-1961) e a Guerra do Vietnã (1946-1976), num segundo momento. Nessa esteira, sob o "impacto da história", ocorre o encontro de Sartre com o marxismo e os comunistas (o “diálogo necessário e impossível” (ANDERSON, 1989) bem como a radicalização de seu pensamento e de suas posições políticas.

\title{
2 DOS OBJETIVOS, DAS HIPÓTESES E DOS MÉTODOS DE TRABALHO
}

Para a consecução dos objetivos, foi elaborada uma hipótese geral de trabalho. A hipótese consiste em afirmar a conexão tangível entre o contexto histórico - o mundo do pós-guerra, as guerras de descolonização, a emergência dos países do Terceiro Mundo e o cenário políticointelectual francês - e a trajetória de Sartre. Portanto, sem a elucidação da conexão entre o contexto histórico e a sua trajetória não seria possível responder "em que momento, em que circunstâncias se faz a súbita adequação entre a atividade de um indivíduo e a corrente profunda da história? Em que momento e através de que mecanismos ela desaparece?” (CHESNEAUX, 1995, p. 156) e, do 
mesmo modo, "por que em determinado momento de sua trajetória Sartre passa a ter um vivo interesse pelo mundo da política, especialmente no Terceiro Mundo”? (MÉSZÁROS, 1991, p. 98). O possível caminho para a resposta se relaciona à compreensão e explicação (GOLDMANN apud LÖWY; NAÏR, 2008, p. 27) do desenvolvimento das posições políticas de Sartre tendo em vista o fracasso da revolução socialista na Europa e, posteriormente, pelo horizonte revolucionário delineado pela emergência do Terceiro Mundo no cenário político mundial, como ainda veremos.

A partir da hipótese geral de trabalho, foram desenvolvidas as seguintes hipóteses específicas: a) certos acontecimentos da história do Terceiro Mundo - a Guerra da Argélia, a Revolução Cubana e a Guerra do Vietnã - radicalizam as posições políticas de Sartre. Os novos problemas engendrados pelas emergências histórica e político-ideológica do Terceiro Mundo nas (pre)ocupações de Sartre permitem-lhe desenvolver análises políticas (de uma atualidade impressionante) acerca dos problemas do colonialismo, da tortura, do racismo, da corrupção, da ideologia revolucionária, do socialismo e da definição de intelectual pela sua função política; b) as análises políticas de Sartre sobre o Terceiro Mundo são tributárias do marxismo e do método dialético. Portanto, não são e nem poderiam ser tributárias de sua filosofia da liberdade e do método fenomenológico. Eis a razão pela qual a emergência do Terceiro Mundo nas (pre)ocupações políticas de Sartre é precedida pela sua "descoberta" do marxismo, cujo método será utilizado na investigação das questões coloniais.

Sob "o impacto da História", Sartre se propõe a tarefas políticas que exigem outras questões à realidade e, consequentemente, um método adequado à interpretação e resolução dessas tarefas, portanto, no horizonte do marxismo enquanto "filosofia insuperável". No entanto, em algumas questões pontuais, como na análise da resistência à tortura, suas concepções existencialistas permanecem; c) as posições políticas de Sartre sobre o Terceiro Mundo expressam a necessidade de intervenção que historicamente certos intelectuais sentem em relação aos embates concretos com os homens das sociedades em que vivem. Na França e em vários países, ao lado de operários, imigrantes africanos, comunistas, estudantes e diversos intelectuais, Sartre participa de debates, conferências, assinatura de manifestos, petições, tribunais populares, passeatas, meetings contra as guerras coloniais, o genocídio e a tortura dos colonizados; d) Sartre (com Frantz Fanon, Patrice Lumumba e muitos outros) foi o divulgador do terceiro mundismo. Por fim, pode-se dizer que Sartre foi um intelectual revolucionário, engajado na transformação da sociedade capitalista, defensor radical da revolução socialista. De acordo com Sartre, esta seria a única capaz de realizar a liberdade entre os homens. Para o desenvolvimento das hipóteses levantadas foi desenvolvido um procedimento adequado que utiliza as seguintes categorias metodológicas: a historicidade, a 
totalidade e a contradição, no que se refere à análise das posições políticas de Sartre relacionadas ao Terceiro Mundo (LÖWY, 2006, p. 15-17).

\title{
3 A EMERGÊNCIA DO TERCEIRO MUNDO E AS (PRE)OCUPAÇÕES POLÍTICAS DE SARTRE
}

Em primeiro lugar, a emergência do Terceiro Mundo nas (pre)ocupações políticas de Sartre deve ser explicada a partir de um duplo movimento: a) pelo malogro da revolução socialista na Europa que ocorre, em parte, pela estratégia stalinista de contenção e consolidação da revolução socialista "num só país" com a subsunção dos partidos comunistas europeus a Moscou; b) pelo novo horizonte histórico revolucionário delineado pela emergência do Terceiro Mundo, com a Guerra da Argélia, a Revolução Cubana e a Guerra do Vietnã.

Nessa esteira, Sartre expressa que

\begin{abstract}
o balanço das forças, no entanto, permanecia favorável provisoriamente ao Ocidente: donde, neste momento histórico, a revolução tornava-se impossível na Europa; nem Churchill, nem Roosevelt, nem finalmente, Stálin a teriam tolerado (...). Hoje, tudo se faz claro: a história era uma só para a terra inteira; advinha daí esta contradição, à época indecifrável, de que a luta de classes cedia lugar a conflitos entre nações - portanto, a guerras adiadas. Hoje em dia o Terceiro Mundo nos aclara; em 1945, não podíamos nem compreender a metamorfose nem tampouco admiti-la. Em resumo, estávamos cegos. (SARTRE, 1962)
\end{abstract}

Em segundo lugar, a emergência do Terceiro Mundo nas (pre)ocupações políticas de Sartre deve ser compreendida levando-se em conta o seu diálogo ("necessário e impossível") com os comunistas e pela sua adoção do método dialético na investigação dos problemas coloniais. A emergência do Terceiro Mundo concretiza, portanto, para Sartre a almejada "terceira-força", tanto em relação ao socialismo soviético como ao capitalismo norte-americano. Logo, isto permite pensar seu posicionamento político de acordo com a luta de libertação do Terceiro Mundo como desdobramento e continuidade do seu conceito de engajamento elaborado no cenário políticointelectual francês no período do pós-guerra. (ALMEIDA, 2009, Capítulo 1).

Sartre pensa que a unidade do Terceiro Mundo está em curso "tanto depois como antes da independência de todos os colonizados sob o comando da classe camponesa" (SARTRE, 1968, p. 140). E não está sozinho pois encontra em Frantz Fanon o mesmo raciocínio segundo o qual os africanos, os asiáticos, e os latino-americanos devem realizar todos juntos e por toda parte o socialismo revolucionário. Do contrário, os colonizados seriam derrotados, um a um.

Enfim, a radicalização das posições políticas de Sartre não é "operada da noite para o dia", mas o resultado de um processo (lento talvez) cujas origens remontam à Segunda Guerra Mundial 
e se aprofundam ao longo dos anos. Assim, é preciso ponderar os termos da asserção de Sartre, segundo a qual "foi a guerra que fez explodir os quadros envelhecidos de nosso pensamento" (SARTRE, 1966, p. 22). Evidentemente, a experiência histórica proporcionada pela guerra é decisiva para a evolução das posições políticas de Sartre. Contudo, os acontecimentos do Terceiro Mundo - a "segunda zona da Revolução Mundial" (HOBSBAWM, 1995) - contribuem de maneira indelével para esse processo de radicalização: a Guerra da Argélia, a Revolução Cubana e a Guerra do Vietnã.

\section{AS POSIÇÕES POLÍticas DE SARTRE SOBRE A GUERRA DA ARGÉLIA (1954- 1962), A REVOLUÇÃO CUBANA (1959-1961) E A GUERRA DO VIETNÃ (1946-1976)}

As posições políticas de Sartre têm como eixo fundamental o problema da liberdade em suas mais diversas manifestações e situações econômicas, sociais, políticas e culturais. O filósofo engagé visita vários países europeus, africanos, asiáticos e americanos, dos Estados Unidos ao Brasil, da Itália à Rússia, da China ao Japão, de Israel ao Egito, com o propósito de defender a liberdade. No entanto, a partir do segundo período pós-guerra, o Terceiro Mundo se torna o centro das (pre)ocupações políticas de Sartre que se engaja na condenação das guerras da Argélia e do Vietnã e na defesa da Revolução Cubana contra os imperialismos francês e norte-americano, respectivamente.

Em relação à África, Sartre afirma que a única maneira de evitar a intervenção estrangeira é a unidade dos objetivos, isto é, a luta pelo "fim dos bombardeios no Vietnã e a abertura de negociações diretas com os vietcongs no quadro dos acordos de Genebra", ou seja, o futuro da África depende da vitória do Vietnã e da derrota dos Estados Unidos, pois, “o que está em jogo no Vietnã, não é nada menos que a dominação do mundo pelos Estados Unidos.” (SARTRE, 1966)

Sartre condena as guerras da Argélia e do Vietnã, do ponto de vista moral, ou seja, como "guerras sujas", pois revelam a "crueldade inumana" que os ricos fazem aos pobres (SARTRE, 1967, p. 9). Apesar de serem "guerras sujas", Sartre afirma que suas suas origens são econômicas. De acordo com o filósofo engagé, para que tenha resultado efetivo, a condenação moral das guerras deve ser feita pelas massas (proletariado e pequena-burguesia). Daí a importância da intervenção do intelectual na divulgação das atrocidades das guerras, do genocídio, da tortura e do racismo junto às massas para obter seu apoio contra a guerra. Todas essas características do engajamento do intelectual têm um objetivo político muito preciso: a transformação da sociedade capitalista pela revolução e a instauração do regime socialista que realizaria o "reino da liberdade".

Em meio à Guerra da Argélia, Sartre define o seu conceito de colonialismo e revela a subhumanização do argelino pela violência colonial que se concretiza no racismo e na tortura. Suas 
posições políticas sobre o evento têm grande impacto na França. A originalidade delas não está no fato de que ele tenha sido o primeiro, ou o único, a constatar a sub-humanização do argelino, mesmo porque não o foi, mas na sua radicalidade. Sartre intervém contra a guerra, divulga suas atrocidades e propõe uma ação política conjunta e coordenada da esquerda, do operariado francês e do campesinato argelino em torno de uma mesma luta: o fim da exploração e da opressão imperialistas.

A radicalidade das posições políticas de Sartre sobre os acontecimentos relacionados à Guerra da Argélia comprova-se de dois modos. Por um lado, exasperou a direita francesa, tanto os gaullistas - que nas passeatas vociferavam "fuzilem Sartre" - quanto a OAS (Organisation de l'Armée Secrét), todos contrários à independência da Argélia. A OAS desferiu, inclusive, dois ataques à bomba ao apartamento de Sartre em Paris. Por outro lado, se opôs à própria esquerda europeia, cujo movimento socialista “com Bernstein na Alemanha, Vandervelde na Bélgica e Jaurès na França era partidário de uma 'política colonial positiva' que não fosse mais a política colonial da burguesia" (FERRO, 1996, p. 208, grifos do autor). Sartre ainda entende que o Partido Comunista Francês transigia com a Guerra da Argélia ao aceitar "fazer o jogo" político-parlamentar burguês (SARTRE, 1960, p. 1).

À época da Revolução Cubana, Sartre já está convencido do peso das circunstâncias sócioeconômicas no condicionamento das ações dos indivíduos. No entanto, e ao mesmo tempo, está convicto da irredutibilidade fundamental das ações dos indivíduos no processo histórico que ele define como liberdade. Para o filósofo engagé, esta irredutibilidade possibilitou a ação revolucionária em Cuba. Mas o "huracán sobre el azúcar" tinha ainda um importante legado para Sartre: mostrava a possibilidade da revolução sem ideologia pré-estabelecida, o que excluía, portanto, a necessidade de mediação do partido político comunista.

A contribuição fundamental de Sartre enquanto "intelectual-jornalista" está na longa série de reportagens publicadas sobre o "huracán sobre el azúcar" (SARTRE, 1961) na França, pelo jornal parisiense France Soir e, no Brasil, pelo jornal carioca Última Hora (ALMEIDA, 2009). Nas reportagens, descreve o esforço cotidiano dos jovens revolucionários para edificar e consolidar a sociedade sob uma lógica para além do capital, com destaque às conquistas sociais obtidas pelo povo cubano, particularmente, no tocante à reforma agrária. As análises de Sartre tanto quanto suas descrições constituem rico manancial para o estudo da obra revolucionária cubana, ainda que nos seus anos iniciais. Não por acaso, Sartre divulga as conquistas sociais cubanas ao público internacional. Com isso, pretende arregimentar apoio à revolução, constantemente ameaçada de aniquilamento pelos Estados Unidos mas também para que sirva de modelo aos países latinoamericanos e, particularmente, ao Brasil. 
A Guerra do Vietnã, descrita e denunciada como "guerra suja", portanto, condenável do ponto de vista moral e, em especial, as atividades do Tribunal Russell radicalizam as posições políticas de Sartre. Justamente, no curso da guerra, ele propõe uma nova relação entre política e moral, com base em sua crítica da política considerada exclusivamente sob o ângulo da eficácia, um dos legados stalinistas. Nessa esteira, a guerra e as atividades desenvolvidas pelo tribunal revelam a Sartre a necessidade e a importância da "inscrição da política no código da moralidade" (MÉSZÁROS, 1991). Eis aí a originalidade das posições políticas de Sartre. De acordo com ele, a partir da "inscrição da política no código da moralidade", as "massas" poderiam avaliar e rejeitar as ações dos governos para além do critério exclusivo da eficácia.

A crítica de Sartre relacionada à consideração da política sob o exclusivo critério da eficácia se dirige tanto aos países capitalistas imperialistas quanto aos países comunistas, mas com a vantagem de que estes colocam o problema sobre aqueles que nem mesmo chegam a cogitá-lo. Porém, Sartre esclarece que a tarefa só pode partir da exigência das "massas", portadoras de uma moral "simples e revolucionária" (SARTRE, 1987, p.181). O intelectual tem papel relevante no processo de desmistificação das ideias que paralisam as "massas" para "despertá-las" do imobilismo. Somente as "massas" podem instituir um verdadeiro tribunal internacional que julgue e efetivamente sancione os crimes de guerra com base em regras éticas e jurídicas.

De acordo com Sartre, papel do intelectual revolucionário, antes de ser "fundido às massas" e perder seu estatuto específico, traduz sua necessidade de intervenção no curso dos acontecimentos históricos. Ele denuncia ainda os crimes de guerra franceses e norte-americanos com o objetivo de informar as "massas" para que formem sua opinião e tomem posições contra as guerras imperialistas e a favor da luta de libertação do Terceiro Mundo. Não apenas a crítica, defende e propõe a unidade da esquerda ao explicitar a "solidariedade de interesses" entre as classes exploradas europeias, particularmente, o operariado e as do Terceiro Mundo, particularmente, os camponeses.

Para Sartre, somente a revolução pode romper com os imperialismos colonialista e neocolonialista, assim como apenas o socialismo pode realizar o "reino da liberdade" entre os homens. Em outras palavras, o "problema humano" - isto é, a liberdade - deve resolver-se em termos de produção e de relações de produção socialistas. Ele não tem dúvidas em concluir: a agressão imperialista é imoral, pois impossibilita ao homem desenvolver-se humanamente ${ }^{1}$. Os colonizadores devem ser responsabilizados e sancionados pelos crimes de guerra. Nesse contexto, afirma o "homem é possível" e, por isso, contradiz sua ideia ontológica de que o "homem é uma

\footnotetext{
${ }^{1} \mathrm{Na}$ esteira de Marx, “a simbiose crítica e revolucionária da teoria com a prática é levada às suas últimas consequências gerando a ação coletiva transformadora do mundo" (DIÓGENES; COSTA, 2021, p. 2076).
} 
paixão inútil". Em outras palavras, a liberdade humana é possível, como provam as revoluções do Terceiro Mundo inscritas no socialismo.

\section{CONSIDERAÇÕES FINAIS}

No curso da Guerra do Vietnã e em meio aos acontecimentos de Maio de 1968, Sartre apresenta uma nova questão: como o intelectual pode converter-se no "povo"?

De acordo com ele, os intelectuais até podem encontrar seus "paraísos", a realização de suas filosofias e de suas expectativas políticas e sociais. No entanto, devem seguir com sua "consciência infeliz" que garante a "não alienação", ou seja, o compromisso para com a verdade. Qualquer verdade, a verdade absoluta? Não. Para o filósofo engagé, o critério de estabelecimento da verdade histórica consiste em (re)conhecer o lado do "mais deserdado", o portador, par excellence, do ponto de vista da universalidade ${ }^{2}$. Diante da verdade, há duas escolhas possíveis para Sartre: a resignação ou a revolução, o engajamento ou a irresponsabilidade, a defesa da ordem capitalista ou a luta pela sociedade socialista.

Entre os anos de 2011 e 2014 surgiram diversas manifestações sociais e políticas - com destaque à participação dos jovens - no mundo todo. Da "Primavera Árabe" aos "Indignados" na Espanha, do "Occupy Wall Street" ao "Movimento Passe Livre e Black Blocs" no Brasil, esses movimentos expressaram, dentre outras coisas, o autoritarismo de diversos governos, a crise de representatividade política da democracia liberal, os elevados níveis de desemprego, a corrupção e o desperdício da utilização de recursos públicos em setores menos essenciais da vida social.

Evidenciou-se, apesar da importância e do grande número de pessoas (e de jovens) reunidos nas manifestações, a falta de coordenação política do movimento que obteve resultados concretos limitadíssimos. Do mesmo modo, ficou patente a ausência da participação efetiva das esquerdas partidárias que, inclusive, foram contestadas e "impedidas" de atuarem junto aos movimentos. Justamente, nesse sentido, determinadas críticas e posições políticas de Sartre podem lançar luz sobre certas questões da ordem do dia. A crítica mais contundente de Sartre às esquerdas partidárias europeias se referia à desunidade dos interesses políticos entre os socialistas e os comunistas acerca do problema colonial. Eis porque a sua proposta mais consistente insistia na necessidade da unidade política das esquerdas na sua luta comum contra o colonialismo.

Não seria esse o problema das esquerdas partidárias brasileiras, isto é, a sua desunidade? Não seria esse o momento de refletirem sobre o seu papel junto às "massas"? Não seria esse o momento de esclarecerem seu projeto político à nação?

\footnotetext{
${ }^{2}$ Para uma melhor e mais aprofundada discussão do tema, vide LÖWY, 2009: pp. 229-255.
} 
São questões políticas fundamentais e atualíssimas à espera de respostas...

\section{REFERÊNCIAS}

ALMEIDA, Rodrigo Davi. Sartre e o Terceiro mundo. São Paulo: Editora da Universidade de São Paulo, 2018.

. Sartre no Brasil: expectativas e repercussões. São Paulo: Editora UNESP, 2009.

ANDERSON, Perry. Considerações sobre o marxismo ocidental. São Paulo: Brasiliense, 1989.

CHALIAND, Gérard. Mitos revolucionários do Terceiro Mundo. Rio de Janeiro: Francisco Alves, 1977.

CHESNEAUX, Jean. Devemos fazer tábula rasa do passado? São Paulo: Ática, 1995.

CONTAT, Michel; RYBALKA, Michel. Les écrits de Sartre. Paris: Gallimard, 1970.

DIÓGENES, Elione M. N.; COSTA, Maria C. F. da S. Marx: o ser e o fazer história. Latin American Journal of Development, Curitiba, v. 3, n. 4, p. 2074-2086, jul./ago. 2021.

FERRO, Marc. História das Colonizações, das conquistas às independências (séculos XII a XX). São Paulo: Companhia das Letras, 1996.

FONTANA, Joseph i. História: análise do passado e projeto social. Bauru/SP: EDUSC, 1998.

HOBSBAWM, Eric. Era dos extremos. O breve século XX. São Paulo: Companhia das Letras, 1991.

LÖWY, Michael e NAÏR, Sami. Lucien Goldmann ou a dialética da totalidade. São Paulo: Boitempo, 2008.

LÖWY, Michael. As aventuras de Karl Marx contra o Barão de Münchhausen. Marxismo e positivismo na sociologia do conhecimento. São Paulo: Cortez, 2009.

. Ideologias e Ciência Social. São Paulo: Cortez, 2006.

MÉSZÁROS, István. A obra de Sartre: busca da liberdade. São Paulo: Ensaio, 1991.

SARTRE, Jean-Paul. Em defesa dos intelectuais. São Paulo: Ática, 1994.

. Escritos Políticos. 3. El intelectual y la revolución. Madrid: Alianza Editorial, 1987.

Terra, 1986.

Sartre no Brasil: A Conferência de Araraquara. (Edição Bilíngue). Rio de Janeiro: Paz e

. Entretien avec Sartre. Interview par Jacques-Alain Miller. Les Cahiers Libres de la Jeunesse, n.1, 15 février 1960. In: CONTAT, M.; RYBALKA, M. Les écrits de Sartre. Paris: Gallimard, 1970.

Prefácio ao Retrato do colonizado, precedido pelo retrato do colonizador. In:

Colonialismo e neocolonialismo. (Situações V), 1968. 
Au Proche-Orient: M. Jean-Paul Sartre fait au Caire l'éloge du président Nasser. Le

Monde. Paris, 5 mars 1967.

Interview - Jean-Paul Sartre et les problèmes de notre temps. In:

. Cahiers Bernard-

Lazare. Paris, n. 4, 1966. de 1962.

Merleau-Ponty vivo (I). In:___ Revista Tempo Brasileiro. Rio de Janeiro, n.2, dezembro

Sartre visita a Cuba. Havana: Ediciones Revolución, 1961.

. Un entretien avec Jean-Paul Sartre: Jeunesse et Guerre d'Algérie. Par K. S. Karol. VéritéLiberté - Cahiers d'information sur la Guerre d'Algérie. Paris, n.3, juillet-août 1960. 